INTERNATIONAL MONETARY FUND

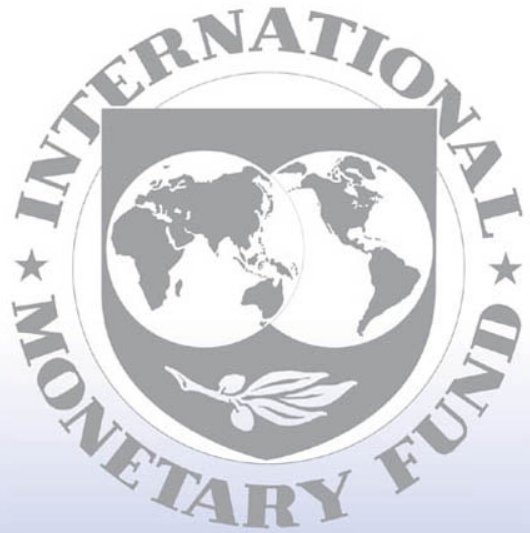

Staff

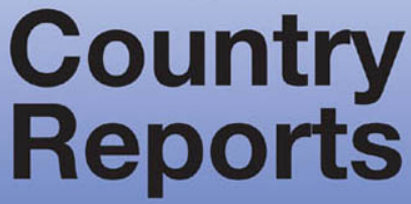




\section{Lao People's Democratic Republic: Joint Staff Advisory Note on the Second Poverty Reduction Strategy Paper and Annual Progress Report}

The attached Joint Staff Advisory Note (JSAN) on the Second Poverty Reduction Strategy Paper and Annual Progress Report for Lao People's Democratic Republic, prepared jointly by the staffs of the World Bank and the IMF, was distributed with the member country's Second Poverty Reduction Strategy Paper and Annual Progress Report to the Executive Boards of the two institutions. The objective of the JSAN is to provide focused, frank, and constructive feedback to the country on progress in implementing its Poverty Reduction Strategy (PRS).

Copies of this report are available to the public from

International Monetary Fund • Publication Services

$70019^{\text {th }}$ Street, N.W. • Washington, D.C. 20431

Telephone: (202) 623-7430 • Telefax: (202) 623-7201

E-mail: publications@imf.org • Internet: http://www.imf.org

Price: $\$ 18.00$ a copy

\section{International Monetary Fund \\ Washington, D.C.}


This page intentionally left blank

(C) International Monetary Fund. Not for Redistribution 


\section{INTERNATIONAL DEVELOPMENT ASSOCIATION \\ AND \\ INTERNATIONAL MONETARY FUND \\ LAO PEOPLE'S DEMOCRATIC REPUBLIC}

\section{Joint Staff Advisory Note on the National Socio-Economic Development Plan 2006-2010 (PRSP) and on the Annual Progress Report}

Prepared by the Staffs of the International Development Association (IDA) and the International Monetary Fund (IMF)

Approved by Jim Adams (IDA)

and David T. Coe and Anthony Boote (IMF)

May 19, 2008

\section{Contents}

I. Overview.

II. Poverty Diagnosis

III. Macroeconomic Policies and Financial Management $\underline{3}$

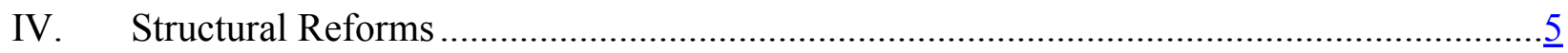

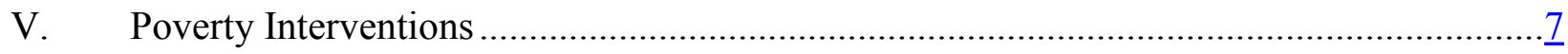

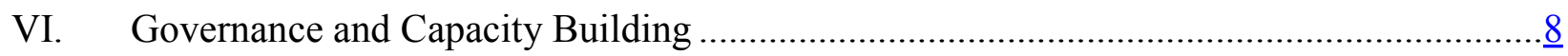

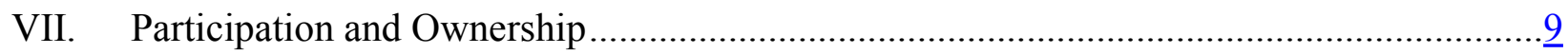

VIII. Monitoring and Evaluation ................................................................................

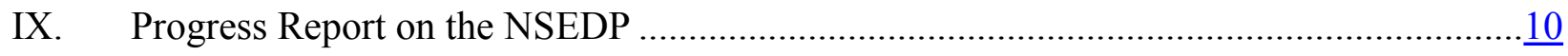

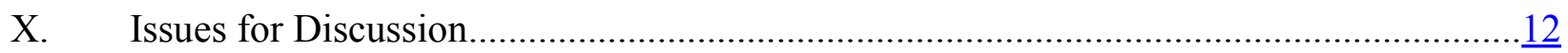




\section{OVERVIEW}

1. The government of Lao People's Democratic Republic (P.D.R.) approved the Sixth National Socio Economic Development Plan (NSEDP) 2006-2010 (PRSP) in June 2006. It builds on the lessons learned and progress achieved under the National Growth and Poverty Eradication Strategy (NGPES), which was presented to the Boards of the IMF and IDA in November 2004 as the first Poverty Reduction Strategy Paper (PRSP). The NSEDP 2006-2010, which was finalized by the government in October 2006 and presented to development partners in November 2006, was expected to be guided by policies in the NGPES and ideally serve as its successor. As part of its monitoring of the Plan, the government issued a separate annual report in November 2007 reviewing progress during the first year of the NSEDP. The staffs have been asked by the government of Lao P.D.R. to consider the NSEDP and Annual Progress Report alongside the IDA's second series of Poverty Reduction Support Operations. Both documents are discussed in this note.

2. The NSEDP provides a comprehensive strategy for development, with a range of medium- and long-term policies aimed at sustained growth and poverty reduction. The Plan recognizes the challenge to the government of integrating the Lao P.D.R. economy regionally and globally and at the same time building critical skills, capacity, and infrastructure to the benefit of all, in view of the continued need for major improvements in social and economic conditions. The NSEDP is anchored by several key pillars. They are (i) human development- and private sector-driven economic growth; (ii) enhanced competitiveness, trade promotion, and regional integration; (iii) social development and focused poverty reduction interventions; and (iv) sound economic governance and gender and ethnic equality.

3. The NSEDP addresses some of the priority areas identified in the JSAN for the first PRSP. ${ }^{1}$ Foremost, it is more poverty and result-focused than the NGPES, also setting out more realistic targets and objectives than in the past plans, including the first PRSP, although in some sectors quantitative targets are still lacking. In addition, sector priorities and policy actions are presented consistently. The staffs also welcome the greater role envisaged in the Plan for improving conditions for private sector development and for further strengthening public financial management. The NSEDP consultation process was also broader than for previous plans, with inclusion of the donor community and private sector for the first time.

4. At the same time, the NSEDP requires some further improvements to strengthen its effectiveness. While macroeconomic and sectoral targets and objectives established in the NSEDP are largely clear, relevant, and achievable, the staffs still view the Plan as lacking adequate discussion of the links between policy actions, intermediate indicators, and final targets and outputs in a number of areas. The resource implications of policy actions also

${ }^{1}$ IDA Report No. 29966 and IMF Country Report No. 04/394; December 2, 2004. 
should be more fully developed and intermediate indicators need to be better defined. The staffs also consider the monitoring and evaluation framework as incomplete. The lack of a comprehensive macroeconomic framework, in particular, raises general concerns about the Plan's impact on fiscal sustainability and potential vulnerability to financing gaps, even though the macroeconomic targets have been met or exceeded so far.

\section{POVERTY Diagnosis}

5. The staffs agree with the poverty diagnosis in the NSEDP, but recognize that achieving the Millennium Development Goals (MDGs) will require major efforts. ${ }^{2}$ Poverty in Lao P.D.R. has reduced significantly, with the poverty headcount declined from 46 percent in 1992/93 to 34 percent in 2002/03, and expected to reach the related MDG target of 25 percent by 2010. Current trends indicate that targets on access to water and sanitation are likely to be achieved, but that those on hunger reduction, universal primary education, and immunization are unlikely to be realized without larger scale interventions.

\section{The NSEDP addresses poverty in Lao P.D.R. through several thematic and} cross-cutting issues, aiming to further its reduction through sectoral and regional development. The poverty reduction strategy seeks to expand economic activity, improve access to basic services, increase internal and health security, and empower decision-making of the poor. It recognizes the role gender equality, good governance, and legal reforms will play in this strategy, as well as how private sector development and natural resource management interplay, to better ensure opportunities and funding in the poverty fight.

\section{The strategy in the NSEDP of targeting poverty reduction programs to the} poorest districts is well justified and supported by sector strategies. The Plan identifies priorities within sectors and adopts a strategy for geographical targeting in the 47 poorest districts. Over the last decade, poverty has declined faster in the poorest (priority) districts than in other (non-priority) districts. However, gaps in accessing health and education between priority and non-priority districts have grown since the early 1990s, driven by more rapid progress in the latter. The NSEDP focus on targeting poverty interventions to the priority districts could help to distribute benefits from growth more equitably.

\section{Macroeconomic Policies and Financial Management}

8. The staffs concur that the macroeconomic policies set forth in the NSEDP are conducive toward consolidating on earlier gains in achieving stability and promoting growth. While growth targets in the NSEDP are ambitious, they are reachable with

\footnotetext{
${ }^{2}$ The poverty diagnosis is based on the 2003 household survey, the 2005 poverty assessment and population census, the 2006 Public Expenditure Review, and MDG monitoring and sector surveys. A Participatory Poverty Assessment (PPA) was released late in the elaboration process, and its findings are broadly consistent with the problems addressed in the Plan.
} 
continued macroeconomic stability, appropriate resource revenue generation and use, wellexecuted structural reforms, and an improved investment climate. The NSEDP sets a growth target of 7.5-8.0 percent each year to 2010 - so far in line with performance in 2006 and 2007, but more than two percentage points higher than decade average preceding the Plan. External demand is the main driver of growth, with substantial foreign direct investment in the resource sector fueling mining and hydropower exports. The NSEDP also envisages domestic demand playing an important role in achieving growth targets, linking it to employment and investment growth in the non-resource sectors.

\section{In the staffs' view, maintaining macroeconomic stability will depend on} developing a more comprehensive macroeconomic and fiscal framework, as a means of better ensuring the soundness and consistency of macroeconomic and sectoral policies and objectives set forth in the Plan. In this context, the NSEDP could benefit from some discussion of fiscal sustainability, in light of the potential volatility in resource revenue (and with some linked to nonrenewables) and continued reliance on external financing. A welldeveloped accounting of the fiscal envelope to achieve the Plan's targets and objectives complemented by a more detailed breakdown of the ODA pipeline and needs would be a good start. The staffs also see further effort needed to strengthen links between the policy priorities identified in NSEDP and actual budget expenditure. In the case of the first PRSP, the 2006 Public Expenditure Review (PER) found weak association between its priorities and spending decisions.

10. The NSEDP recognizes the key role that sound public financial management will play in achieving effective poverty interventions and outcomes. Implementation of the Public Expenditure Management Strengthening Program (PEMSP), with support from the World Bank (IDA), is emphasized in the Plan. Under the guidance of the PEMSP, actions are being taken to improve fiscal planning, budget preparation and execution, and financial reporting in order to strengthen accountability and transparency, including at the local level as recommended by the latest PER. The PEMSP has been developed through consultative workshops at the provincial and national level to ensure clearer understanding and consensus, as noted in the Plan. Some measures have already been taken to strengthen fiscal planning and reporting, with publication of general budgets and outturns in the Official Gazette since 2002, albeit with a significant delay. More detailed budgets are now published, starting with priority sectors. The government has also initiated efforts to upgrade its budget monitoring system, develop quarterly budget execution reports, and introduce a Chart of Accounts according to international standards. More timely reporting and broader dissemination of data and information on public finances will improve the monitoring and evaluation of fiscal operations.

\section{The staffs welcome the government's commitment in the NSDEP to address} central-local fiscal issues. Local authorities' accountability and transparency to the central government remains weak, with over 75 percent of spending on priority sectors executed at the local level. The Budget Law adopted in 2006 aims to reassert the central government's 
fiscal authority. Implementation regulations delineate the roles and responsibilities of the various levels of government, facilitate a swift centralization of Treasury management and customs and tax administration, and establish apportionment rates for shared taxes. At the local level, more progress will be needed in improving government accountability, collecting select revenues, and strengthening spending efficacy.

\section{The government has prepared a prioritized list of public investment projects in} the NSEDP, in support of achieving sustained growth. These projects will be financed mainly through concessional facilities, although the Plan also mentions possible commercial borrowing for large investment projects. The last joint Bank-Fund staff Debt Sustainability Analysis stressed that new borrowing should be on concessional terms to ease the external debt burden, which remains at elevated levels. The financing plan for the NSEDP reflects a comprehensive view of investment needs without due consideration to aid availability. The government's intention to guide its and donors' investment decisions through prioritized sector spending programs is a prudent move, especially in the event of aid shortfalls, which have materialized in the past.

\section{However, with the long list of energy sector projects in the NSEDP, the staffs urge careful attention to funding availability, implementation capacity, and debt} sustainability. The energy sector strategy in the Plan is sound and consistent with other sector strategies and policies. However, the investment list needs prioritizing to ensure consistency with the investment program and financial capacity of Electricité du Laos. The government is advised to review the implementation capacity on ongoing projects, as well as reassess its strategy of direct equity participation in mining and hydropower projects, with a view to limiting debt-creating obligations that could arise from government direct ownership. It should also establish mechanisms to systematically review links between hydroelectric projects and irrigation potential when making investment decisions, build capacity for evaluating hydropower investments, and strengthen social and environmental safeguards.

\section{The NSEDP should also recognize more the need for capacity building in} monetary management, including through technical assistance. As the economy further opens and financial sector develops, the use of more market-based instruments will enable the Bank of Lao P.D.R. (BoL) to better manage inflows and ensure price stability. Improved quality, frequency, and availability of monetary and financial market information will be essential to policy formation.

\section{StRuCTURAL REFORMS}

15. The staffs view the NSDEP's agenda for structural reform as ambitious but achievable, and welcome its focus on further strengthening the role of the private sector. The Plan emphasizes improving the investment climate, primarily through strengthening and streamlining the legal underpinnings of private sector activity, namely property rights protection and the overall business regulatory framework. The government 
has recently taken steps in this direction, approving a new Enterprise Law, drafting a small and medium-sized enterprises (SME) development strategy, and establishing an SME office and a one-stop-shop for investment licensing. It has also piloted a one-stop service at a border posts, issued directives to remove all but Customs, Quarantine, and Immigration agencies from borders, and streamlined import and export licensing. The effective implementation of the Enterprise Law will be key to strengthening the private sector's role and simplifying business regulations. The NSEDP rightly identifies moving from a business licensing to a registration system as a priority for implementation. Related laws, particularly the law for domestic and foreign investments, should also be harmonized with the Enterprise Law, to facilitate ease of entry and operation. Other priorities include improving the provision of business services, reforming the banking system to enhance credit access, and speedy implementation of the SME strategy.

\section{Complementing efforts to streamline business regulation are plans to develop} and strengthen financial sector, but the staffs see a need for more concrete policy actions. The NSEDP's commitment to reforming the legal framework for banking and credit organizations and creating a level-playing field between state-owned commercial banks (SOCBs) and privately-owned banks are steps in the right direction. To this end, a new Commercial Bank Law was approved in 2006, but given the slow pace of banking reform in recent years, full implementation of the law requires renewed impetus. Strategic partners for the larger SOCBs should also be identified to strengthen their financial conditions and upgrade their operational capacity. Improving the BoL's bank supervisory capacity will also be critical to ensuring banking system soundness. To address the range of credit needs in Lao P.D.R., the NSEDP also encourages micro-finance institutions, in part through implementation of plans developed by the Rural Microfinance Committee. Regulations are being established to guide activities of various micro-finance related funds and institutions, but they will need to be consistent with ensuring the sustainability of operations.

\section{The NSEDP reaffirms the government's aim to limit direct assistance to state- owned enterprises (SOEs), but the staffs would welcome a clearer statement of their envisaged role. The Plan notes efforts to terminate direct government lending to SOEs or underwriting loans to them from the SOCBs, so as to better manage fiscal risks. It also calls for their reorganizing, consolidating, or dissolving those in the agriculture and forestry sector. However, the Plan remains vague in terms of resolving problems associated with other ineffective SOEs, only noting plans to revive the legal framework to ensure state enterprises are open to fair competition.}

18. The NSEDP also reaffirms the government's commitment to trade liberalization. It identifies export promotion as key to development and stresses the economic benefits of further regional and global economic integration. The staffs concur with the strategy to raise competitiveness through implementing commitments under ASEAN and other bilateral and multilateral agreements as well as taking further steps toward WTO accession. To enhance competitiveness, further reductions in tariff and non-tariff barriers, a modernization of 
customs operations, and implementation of ASEAN's single window and rules of origin would be welcome.

\section{POVERTY INTERVENTIONS}

19. Focusing on the key poverty interventions in the NSEDP, the staffs view the education strategy as generally sound, but budget allocations will underpin successful implementation. The Plan appropriately recognizes the key importance of universal enrollment in primary education, in line with the Education for All Program (EFA). While recurrent education budget has been growing as a share of the total budget in recent years, declining level of teacher salaries relative to per capita GDP raise questions about effective priorities. This trend will need to be reversed to meet EFA targets and education-related MDGs, as well as be accompanied by civil service reform. Priority should be given to setting indicative per capita budget allocations for basic education and improving financial management information to better ensure outcomes.

20. The NSEDP's health strategy appropriately focuses on expanding primary and preventive care, but budget allocations and sector policies here, too, will need to better reflect these priorities. In particular, the Plan seeks to improve access to and quality of maternal and child health care. It also recognizes important cross-sectoral determinants of health outcomes, like clean water and sanitation. Making health-related spending top priority in annual budget is necessary in order to provide essential health services to the poor and mitigate some of the impact of health user fees. The government should also consider introducing a more transparent, needs-based formula for resource allocation across districts.

\section{The NSEDP properly emphasizes the importance of agriculture and rural} development for poverty reduction, primarily by increasing farmers' capabilities and competitiveness. A continuation of government support for the agricultural sector is indicated, including promotion of commercial agriculture, agricultural exports, and product diversification, as well as off-farm diversification for rural populations. The Plan prioritizes the introduction of new technology, including IT, in production, preservation, and processing and the strengthening of extension services and skills training for farmers and other rural population. It also recognizes the need to improve farmers' market access and competition through rural roads development. Improved resource allocation and better financial management are needed to improve distribution of public funds between richer and poorer districts and accountability for their use. The staffs also note that the Government should strengthen its analytical base for further understanding of effective poverty reduction approaches in the country, including addressing challenges related to the relocation program.

\section{The NSEDP outlines sound strategies for improving road coverage and} maintenance and broadening access to electricity supply and clean water. The road strategy balances regional and national connectivity, and aligns donors to a sector-wide approach and a prioritized and costed public investment plan. The staffs support this strategy 
and encourage the government to implement its medium-term road maintenance and investment program, including promoting private sector participation. Access to electricity has already been expanded from around 16 percent of households in 1995 to almost 50 percent by 2006 , but delivery to remote rural communities remains a challenge. Rural power supply is expected to be addressed through various public-private sector delivery models in the context of the newly established Rural Electrification Fund. The government will need to be mindful not to allow the heavy investment program in electricity exports by Electricité du Laos to crowd out critical investment plans for domestic rural electrification. Lao P.D.R. has also made good progress in expanding access to safe water and sanitation over the last decade, and the NSEDP rightly supports the continuation of these efforts. Reaching 2010 targets, however, will require decentralized delivery through community participation and cost sharing and continued donor support.

\section{Governance AND CAPACITY BUILDING}

\section{The NSEDP recognizes better governance in Lao P.D.R. as critical to achieving} its overall objectives. The focus is on improving public service delivery, enhancing transparency and participation in policy-making, and strengthening the rule of law. To better address corruption, the government has passed a new anti-corruption law and strengthened the State Inspection Agency (SIA). The staffs encourage the government to complete and implement the supporting regulations related to the law and allow the SIA to operate with the appropriate authority. The NSEDP also aims to improve public knowledge of rights and obligations, including women's legal awareness and access to the judiciary. Legal literacy programs will be conducted in schools and villages, with particular emphasis on the local level where knowledge is more limited. The government will also create the legal basis for the progressive public circulation of court decisions and judgments.

\section{The staffs see improving the governing framework for the mining sector will be} an important priority, given the sector's contribution to growth. The NSEDP aims to expand mining sector operations and move Lao P.D.R. up the value-added chain in the mining industry. To this end, the Plan seeks to ensure greater transparency in investment regulations and consistent application of relevant laws. The staffs encourage the government to clearly spell out the sector strategy and policy framework for improving the business investment climate in general and mining specifically, in line with efforts to clarify and streamline business regulation. The staffs also place some urgency on reviewing the fiscal regime governing natural resource revenue, including respective roles and terms of public and private financing of such projects, with greater level of transparency and accountability. In the mining sector, in addition to strengthening public financial management and accountability at the central level, systems will need to be in place at the provincial level to ensure mining royalties collected there are used as intended. Given its growing importance, whether resource revenue accrues to local or central government will need further clarification. Sustainable natural resource management should also build on ongoing good practices in transparency and environmental and social sustainability. 
25. The NSEDP appropriately identifies capacity building as a critical area for plan implementation and identifies actions for most sectors. In particular, the Plan seeks priority interventions in macroeconomics and public financial management, community participation and private sector development, legal and judicial areas, and natural resource and road/transport management. Actions are geared toward developing individual skills, but the Plan should also devote sufficient attention to improving organizational capacity. The staffs advise the government to consider preparing sectoral capacity development frameworks that are coordinated with interventions at the institutional level. Such frameworks could also be useful in the areas of health, education, agriculture, and forestry. Strategies would also be more effective if accompanied by baselines and needs assessments.

\section{PARTICIPATION AND OWNERSHIP}

26. A more comprehensive planning process was followed in the NSEDP than for previous plans. The Ministry for Planning and Investment (MPI) and line ministries led consultations with local communities, focusing on the poorest districts. Through the semiannual Private Sector Development Forum and mini-Round Table Meetings (RTM), the private sector, donor community, and foreign NGOs were also consulted for the first time. Other participants included National Assembly members and mass-organizations like the Lao P.D.R. Women's Union. Cooperation across government was strong, with the CPI leading frequent technical meetings with the Ministry of Finance and line ministries. The NSEDP describes the participatory process, but does not report on the comments provided, making it difficult to determine how consultations shaped the Plan.

\section{The staffs see the development of a comprehensive NSEDP dissemination} strategy and progress reports as important to plan implementation. Previously, a lack of awareness of plans existed across government ministries, among local governments, and at the individual level. The NSEDP is currently posted on the RTM website, and the government has disseminated it via the press and through local government workshops. Communication of the NSEDP could be extended by translating it into minority languages and creating a NSEDP-dedicated website. It would also be desirable for results to be reported on an ongoing basis and for regular stakeholder feedback to be sought.

\section{Monitoring AND Evaluation}

28. The staffs note the further improvements are needed in monitoring implementation and evaluating outcomes under the NSDEP. As noted, the NSDEP should be underpinned by a comprehensive macroeconomic framework. Lacking this, it is difficult to assess the consistency of the government's policy objectives and budgetary resource availability, leaving the potential for large financing gaps and heightening concerns about overall fiscal sustainability. The authorities are currently working to develop mediumterm macroeconomic, fiscal, and expenditure frameworks, which the staffs urge finalization as earliest possible as a critical guide for policy formulation and monitoring. To this end, the staffs note that a number of development partners, including the World Bank, signed the Vientiane Declaration of Aid Effectiveness in November 2006, which recognizes the need to 
align donor assistance with government priorities, including those laid out in the NSEDP, and to establish sound monitoring and evaluation framework to enable government Lao P.D.R. and its development partners to measure progress.

\section{The NSEDP presents a MDG-based summary targets table, but lacks a full-} fledged monitoring and evaluation framework. The summary indicators table presents a well-formed view of the most critical objectives of the Plan and their corresponding targets. A comprehensive monitoring and evaluation framework could build on the MDG-based summary table and be supplemented by other relevant targets to the NSEDP, including quantitative ones. The framework should link input, output, and impact indicators for each sector to allow for proper monitoring and evaluation. This framework will also be critical to improving accountability and providing feedback to policy makers.

\section{The staffs also note the need to build human and institutional capacity in} monitoring and evaluating the NSEDP. In particular, skills in the public sector in data analysis and processing require considerable strengthening, especially at lower administrative levels. Communication between different administrative units also needs to be significantly improved. Line ministries also need to regularly collect and provide appropriate data to the National Statistics Center for proper monitoring of impact indicators.

\section{The NSEDP should also place a larger priority on improving the breadth and} quality of statistics. On macroeconomic data, the lack of timely and reliable statistics on the national accounts and balance of payments (as well as on the earlier noted fiscal accounts) severely limits the monitoring of some basic welfare indicators and key economic activities Data on annual poverty indicators in some critical areas, including food intake, housing and education, and health care, also needs to be improved. The National Statistics Law planned for 2008 aims to increase the autonomy of the National Statistics Center. Additional training programs for statisticians will be required to strengthen their capacity.

\section{PROGRESS REPORT ON THE NSEDP}

\section{The government has prepared an annual progress report that assesses} implementation of the NSEDP in the first year and sets out main priorities in the second year. The report titled Achievements, Constraints and Future Direction Within the Implementation of the NSEDP 2006-2010 was prepared in consultation with the working groups jointly chaired by the government of Lao P.D.R and development partners and presented at the Round Table Implementation Meeting in November 2007, along with line ministries presentations on the quantitative and qualitative progress against key baselines. Subsequently, it has been published on the government's Round Table meeting website, and general progress on the NSEDP has been reported in the local media.

33. The progress report focuses on the following areas: (i) macroeconomic performance; (ii) three cross-cutting issues - the MDGs, poverty reduction, and governance; (iii) four sectoral areas - agriculture and forestry, education, health, and transport; and 
(iv) donor coordination and ODA management. Achievement and developments in each area are compared against select NSEDP targets to assess progress.

34. The progress report notes that the government's macroeconomic targets for the first year of the NSEDP have been broadly met or exceeded-notably for the budget and growth. With regard to the 2006/07 budget, the report lists some key measures taken in the first year underpinning budget performance, citing improvements to the public financial management framework and supporting this, adoption of a new Budget Law, among other key legislation. The government more than achieved its budget deficit target in the NSEDP for 2006/07 on substantially higher than projected revenue, financed through external concessional loans and grants. Performance so far in the first half of 2007/08 suggests the government will outperform again on its NSEDP deficit target in the current fiscal year. The report also notes that planned increases in budgetary allocations were made in key sectoral areas, including in education and health. The report notes better than expected real GDP growth in most sectors in 2006/07, with the notable exception in agriculture. The report could expand on why agriculture experienced output shortfalls and how the NSEDP can be effective in improving sector prospects.

35. With regard to the MDGs, the progress report highlights that progress so far on several goals has not been adequate to reach the targets set in the NSEDP. While the government expects the MDG targets of halving poverty and reducing child mortality to be achieved by 2015, reaching other MDGs may be more challenging. The report could provide some practical approaches on accelerating progress toward achieving the MDGs or otherwise ways to redirect efforts to a prioritized set of MDGs. For example, more attention should have been placed on reducing child malnutrition and on reporting of progress in this area. To better monitor progress on the MDGs, the staffs also urge the government to improve annual reporting in the social sectors, for example, by using data consistent with line ministries' internal reporting mechanisms, such as Education Monitoring Information System, Health Monitoring Information System, and the Multi-Indicator Cluster Survey.

36. The progress report reinforces the need for more comprehensive frameworks for reporting targets and outturns to improve overall transparency and accountability, as noted in assessing the NSEDP. The report highlights key macroeconomic and sectoral outcomes. Based on first-year performance, targets and objectives are revised for the second year. However, the report could benefit from a more systematic comparison of targets versus outcomes in the first year and discussion of necessary adjustments in the second year and beyond, including links to specific policy actions. In the future, the staffs suggest that a dissemination strategy for the NSEDP include more specific reporting of annual monitoring and evaluation results. The staffs also note that more discussion is needed on monitoring and evaluating trade-related, financial sector, and state enterprise reforms and more generally on improvements to the investment climate, to highlight progress achieved in each of these areas, notably operational and financial restructuring at the larger SOCBs and SOEs. 


\section{ISSUES FOR DISCUSSION}

37. The NSEDP provides a good basis for continued growth and poverty reduction, but would benefit from further improvements to strengthen its effectiveness. The Plan envisages critical interventions in macro-fiscal management, structural reforms, and human resource and infrastructure development, and sets relevant and realistic targets in poverty reduction and other key areas. Importantly, it recognizes the private sector as a driving force for accelerating growth and reducing poverty and articulates policies to provide an increasingly supportive investment climate. These policies are complemented by comprehensive strategies for infrastructure, rural and social development, and environmental protection for sustainable, export-driven growth. On the other hand, more discussion is needed in a number of areas on the links between policy actions, intermediate indicators, and final targets and outputs, supported by a stronger monitoring and evaluation framework. Incorporation of a comprehensive macroeconomic framework, in particular, would provide a clearer view of the Plan's impact on fiscal sustainability and consistency with available financing.

\section{Overall, the staffs have identified five priority areas for implementation where} the NSEDP policies need further elaboration, clarification, and effective implementation to ensure the success of the strategy. They are: (i) maintaining macroeconomic stability and promoting private-sector led growth by improving the investment climate, reforming the banking sector, and continuing trade liberalization; (ii) elaborating macroeconomic and fiscal frameworks (including in the context of preparation of the 2008/09 budget), an NSEDP dissemination strategy, and a comprehensive monitoring and evaluation framework; (iii) strengthening public financial management, especially by fully implementing the new Budget Law; (iv) creating stronger links between NSEDP objectives of poverty reduction and actual budget policy; and (v) improving transparency and accountability, especially at the local level, and the breadth and quality of statistics.

\section{The staffs would like to ask whether the Executive Directors concur with the} staffs' views that the NSEDP has: (i) incorporated the necessary elements of the poverty reduction strategy (PRS) principles and presents a good basis to deliver growth and poverty reduction; (ii) adequately characterized implementation risks; and (iii) identified the priority areas for implementing a poverty reduction strategy. The staffs would also ask whether the Executive Directors concur that the first-year progress report provides an adequate overview of implementation so far of the NSEDP, but that PRS and future progress reports could benefit from a more systematic presentation, monitoring, and evaluation of macroeconomic and sector-specific indicators, including formulation of more comprehensive and supportive frameworks, to ensure better ensure targeted outcomes over the Plan period. 